\title{
The therapeutic potential of the cerebellum in schizophrenia
}

\author{
Krystal L. Parker ${ }^{1}$ *, Nandakumar S. Narayanan ${ }^{1}$ and Nancy C. Andreasen ${ }^{2}$ \\ ${ }^{1}$ Department of Neurology, University of lowa, lowa City, IA, USA \\ ${ }^{2}$ Department of Psychiatry, University of lowa, lowa City, IA, USA
}

\section{Edited by:}

Thomas C. Watson, University of

Bristol, UK

\section{Reviewed by:}

Detlef H. Heck, University of

Tennessee Health Science Center,

USA

Pauline Yvanne Obiang, Centre

national de la recherche

scientifique, France

${ }^{*}$ Correspondence:

Krystal L. Parker, Department of

Neurology, University of lowa, 2110

MedLabs, lowa City, IA 52242, USA

e-mail:Krystallynn.parker@

gmail.com
The cognitive role of the cerebellum is critically tied to its distributed connections throughout the brain. Accumulating evidence from anatomical, structural and functional imaging, and lesion studies advocate a cognitive network involving indirect connections between the cerebellum and non-motor areas in the prefrontal cortex. Cerebellar stimulation dynamically influences activity in several regions of the frontal cortex and effectively improves cognition in schizophrenia. In this manuscript, we summarize current literature on the cingulocerebellar circuit and we introduce a method to interrogate this circuit combining opotogenetics, neuropharmacology, and electrophysiology in awakebehaving animals while minimizing incidental stimulation of neighboring cerebellar nuclei. We propose the novel hypothesis that optogenetic cerebellar stimulation can restore aberrant frontal activity and rescue impaired cognition in schizophrenia. We focus on how a known cognitive region in the frontal cortex, the anterior cingulate, is influenced by the cerebellum. This circuit is of particular interest because it has been confirmed using tracing studies, neuroimaging reveals its role in cognitive tasks, it is conserved from rodents to humans, and diseases such as schizophrenia and autism appear in its aberrancy. Novel tract tracing results presented here provide support for how these two areas communicate. The primary pathway involves a disynaptic connection between the cerebellar dentate nuclei (DN) and the anterior cingulate cortex. Secondarily, the pathway from cerebellar fastigial nuclei (FN) to the ventral tegmental area, which supplies dopamine to the prefrontal cortex, may play a role as schizophrenia characteristically involves dopamine deficiencies. We hope that the hypothesis described here will inspire new therapeutic strategies targeting currently untreatable cognitive impairments in schizophrenia.

Keywords: schizophrenia, cerebellum, anterior cingulate, cognitive symptoms, optogenetic stimulation

\section{INTRODUCTION}

The purpose of this theory and hypothesis manuscript is two fold. First, we review the role of the cerebellum in cognition and schizophrenia, the anatomy of cerebellar projections to frontal cortex, and the available evidence indicating that the cerebellum influences the frontal cortex. Second, we introduce the novel hypothesis that optogenetic cerebellar stimulation may ameliorate cognitive symptoms of schizophrenia by normalizing frontal activity, and we propose testable animal and translational experiments to probe this hypothesis. Studies have shown that connections exist between the frontal cortex and cerebellum and that cerebellar stimulation improves cognitive symptoms of schizophrenia; to our knowledge, this manuscript is the first to propose a method to pharmacologically disrupt frontal function in rodents to mimic abnormalities in schizophrenia, document cognitive dysfunction similar to that reported in schizophrenia, and use cerebellar stimulation to restore frontal activity and rescue cognition. Specifically, we will evaluate the therapeutic potential of the cerebellum by introducing a technique to interrogate cerebellar connections to the frontal cortex using combined opotogenetics, neuropharmacology, and electrophysiology in awake-behaving animals while minimizing incidental stimulation of neighboring cerebellar nuclei.

The cerebellum is a critical component in tasks of both motor and cognitive origin. Thalamic connections between the cerebellum and frontal cortex create the potential for the cerebellum to powerfully influence cognition. In schizophrenia, there are abnormalities in all three regions, which led to the hypothesis that a distributed network involving the cerebellum contributes to cognitive deficits. We, and many of our colleagues, have been investigating this circuit for almost two decades (Leiner et al., 1994; Andreasen et al., 1998; Schmahmann, 1998, 2010; Andreasen and Pierson, 2008). Although studies of functional neuroimaging, anatomy, positron emission tomography (PET), and structural and functional magnetic resonance imaging are extensive, it is unclear how this circuitry is influenced by schizophrenia (Alphs, 2006). The advent of molecular tools and imaging technology such as tractography and diffusion tensor imaging (DTI) that can be used in psychiatric disorders have provided additional clarity to this issue (White et al., 2008). 
Cognitive impairments in schizophrenia including executive dysfunctions in working and episodic memory, (Andreasen et al., 1999; Ragland et al., 2009), attention, reasoning, and timing (Carroll et al., 2009), remain untreatable (Alphs, 2006). These impairments have been described as cognitive dysmetrias, or disruptions in the synchronous coordination of cognitive capacities (Andreasen et al., 1998; Schmahmann, 1998). Recently, Demirtas-Tatlidede et al. reported that cerebellar vermal theta burst stimulation (TBS) has been effective at relieving some cognitive symptoms in treatment-resistant schizophrenia patients (Demirtas-Tatlidede et al., 2010). Specifically, eight schizophrenia patients were evaluated using comprehensive neuropsychological testing, Positive and Negative symptoms subscale (PANSS), Clinical Global Impression (CGI), Calgary Depression Scale for schizophrenics (CDSS), Profile of Mood States (POMS), and Visual Analogue Mood Scale (VAS) for dimensions of mood (Happiness, Sadness, Calmness, Anxiety, Wellbeing, Anger, Selfconfidence, Fear, Alertness, and Energy). Subjects received cerebellar vermal TBS twice daily on 5 consecutive days for a total of 10 stimulation sessions. Baseline ratings were compared with ratings immediately following stimulation and 1 week later. The results showed significant improvement in negative symptoms reported by the PANSS both following treatment and at followup, and there was a significant elevation in mood. Cognition also improved as the subject had fewer working memory omissions with no worsening of other measures.

The mechanism underlying the efficacy of cerebellar stimulation in schizophrenia is unknown. Studies have shown that electrically stimulating the cerebellum produces downstream changes in the prefrontal cortex and anterior cingulate cortex (Mittleman et al., 2008; Rogers et al., 2011, 2013; Watson et al., 2014). Connections between the cerebellum and anterior cingulate, comprising a cingulocerebellar circuit, are of particular interest because they have been confirmed to exist by tracing studies, they are conserved between species including humans, primates, and rodents, and structural and functional abnormalities are present in schizophrenia. Here, we present empirical evidence that (1) the deep cerebellar nuclei and anterior cingulate cortex are disynaptically connected via two separate pathways (the thalamus and the ventral tegemental area-VTA) allowing the cerebellum access to the frontal cortex; and (2) the cerebellum may modulate frontal neuron ensembles. This cerebellar modulatory mechanism has the potential to be harnessed to rescue abnormalities in the anterior cingulate, typically associated with schizophrenia. The mechanism underlying the efficacy of cerebellar stimulation needs to be illuminated if cerebellar stimulation is to become a therapeutic treatment strategy for the negative and cognitive symptoms of schizophrenia (Demirtas-Tatlidede et al., 2013).

\section{CINGULOCEREBELLAR INTERACTIONS IN SCHIZOPHRENIA FUNCTIONAL NEUROIMAGING}

Cognitive dysmetria has been probed in patients with schizophrenia (Andreasen and Pierson, 2008) concurrently undergoing neuroimaging using tasks such as recall of complex narratives (Andreasen et al., 1995a), episodic memory (Andreasen et al., 1999; Ragland et al., 2009), memory for word lists (Andreasen et al., 1995b; Paradiso et al., 1997; Crespo-Facorro et al., 1999), recognition memory (Crespo-Facorro et al., 2001), dichotic listening (O'Leary et al., 1996), eyeblink conditioning (Parker et al., 2013b; Figure 1), and timing (Volz et al., 2001). These data consistently indicate lower blood flow in the cerebellum and frontal cortex (Andreasen et al., 1997) including medial frontal regions such as the anterior cingulate (Adams and David, 2007).
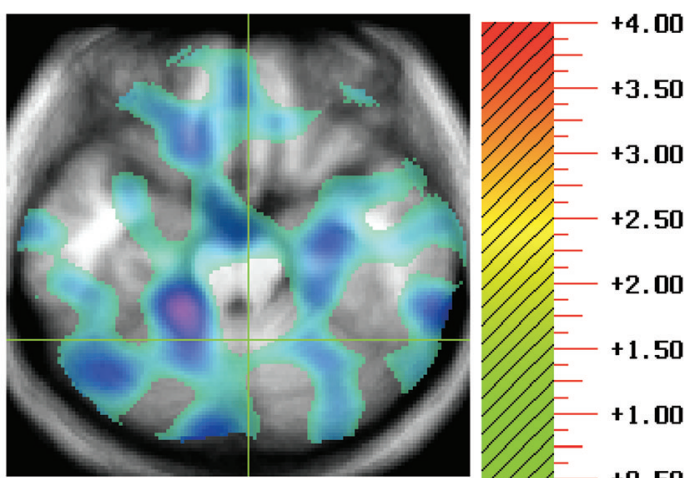

$+4.00$
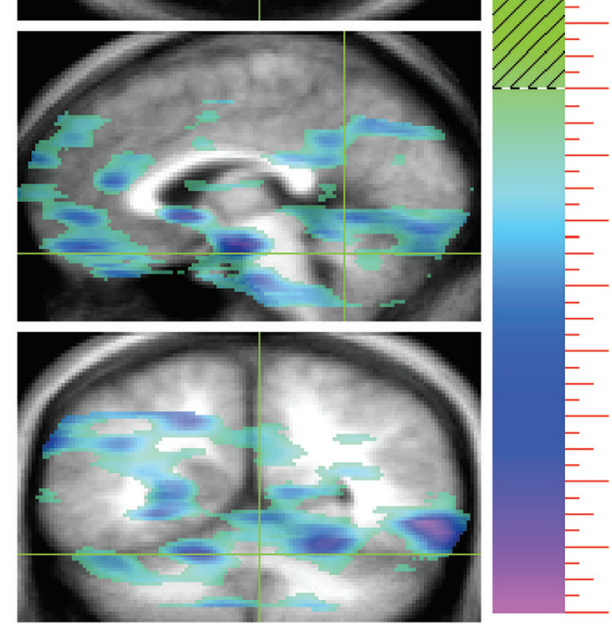

$+0.50$

$+0.00$

$-0.50$

$-1.00$

$-1.50$

$-2.00$

$-2.50$

$-3.00$

$-3.50$

$-4.00$

FIGURE 1 | During positron emissions tomography (PET) imaging of a task typically thought to be cerebellum dependent, eyeblink conditioning, hypofunction was revealed in the cingulocerebellar circuit. A double subtraction method where the baseline

pseudoconditioning phase of unpaired tones and airpuffs was first subtracted and then the rCBF for patients with schizophrenia was subtracted from that of controls, show negative peaks indicating patients with schizophrenia have less rCBF than controls. This representative image shows hypofunction of the anterior cingulate (Talairach coordinates: $-1,30$, 14) and cerebellar lobules IVN, and IX (Talairach coordinates: $-3,-67,-17$ ) in patients with schizophrenia in comparison to healthy controls. For each illustration there are three orthogonal views per row with transaxial on the top, sagittal in the middle, and coronal on the bottom. Green crosshairs are used to show the location of the slice. Images follow radiological convention and show location as if facing the patient where the left side of the image represents the patient's right side. The statistical maps of the PET, showing the regions where the two groups differed significantly at the 0.005 level, are superimposed on a composite magnetic resonance image (MRI) derived by averaging the MR scans from the subjects. Regions in $\mathrm{red} /$ yellow tones indicate positive peaks (greater activation in patients than in controls) and regions with blue/purple indicate negative peaks (less activity in patients than controls). The statistical results are portrayed using the value of the associated $t$-statistic, which is shown on the color bar on the right. The images are referred to as "t maps" showing all voxels in the image which exceed a display threshold. 
The correlation of these cognitive deficits with abnormal regional cerebral blood flow, led to the mechanistic explanation that abnormalities in a distributed cerebellar neural circuit may underlie cognitive impairments in schizophrenia (Andreasen et al., 1998). Aberrant connections from the cerebellum to the cerebral cortex may influence misconnections between percepts and their meanings, in turn causing errors in perceptual binding and misinterpretations of many kinds (e.g., delusions, hallucinations); they may also lead to inefficient or inaccurate information processing, forming the basis for the multiple types of cognitive impairments observed in schizophrenia (Andreasen et al., 1998; Wiser et al., 1998; Schmahmann, 2004).

The precise networks that are dysfunctional in schizophrenia remain elusive. Of particular interest is the anterior cingulate (Brodmann Areas 24/32) for its involvement in normal cognition and executive functioning including working memory, attention, emotional processing, response inhibition, performance monitoring, and timing (Devinsky et al., 1995; Narayanan et al., 2005, 2013; Picton et al., 2006; Cavanagh et al., 2009; Prabhakaran et al., 2011; Gasquoine, 2013). In addition, the anterior cingulate is consistently hypoactive in schizophrenia during cognitive tasks (Adams and David, 2007) such as random number generation (Artiges et al., 2000; Meyer-Lindenberg et al., 2001), error detection (Carter et al., 2001), monitoring self-performance (Carter et al., 1998, 2001), Stoop Tasks (Yücel et al., 2002; Minzenberg et al., 2009), continuous performance (Honey et al., 2005), and timing (Volz et al., 2001). Many of these studies found correlated cerebellar functional abnormalities (Honey et al., 2005; Koziol et al., 2013). These data provide evidence that cognitive impairments in schizophrenia may result from abnormalities in the cingulocerebellar circuit.

\section{STRUCTURAL ABNORMALITIES}

In addition to hypofunction, studies report structural abnormalities in the anterior cingulate, thalamus, and cerebellum in schizophrenia. Specifically, voxel based morphometry (MouchetMages et al., 2011) and DTI (Wiser et al., 1998) reveal abnormalities in white matter connectivity between the nodes of the cingulocerebellar circuit in schizophrenia. The presence of structural abnormalities in these structures supports abnormalities in the distributed cerebellar network.

The cingulum bundle, including the anterior cingulate, has consistently shown abnormalities in schizophrenia (White et al., 2008). Patients with schizophrenia have an overall reduction of gray matter in the anterior cingulate (Brodmann Area 32) (Glahn et al., 2008; Takayanagi et al., 2013; Salgado-Pineda et al., 2014). Post mortem studies revealed a reduction in laminar thickness in the anterior cingulate (dorsal and subcullosal regions) (Fornito et al., 2009). Mitelman et al. report that schizophrenia patients with better outcomes have correspondingly higher fractional anisotropy (FA) than normal in frontal white matter areas including bilateral cingulate gyri; emphasizing the integral role of the anterior cingulate, he proposed that this increased FA in cingulate white matter may serve a neuroprotective role as indicated by a better outcome for patients (Mitelman et al., 2006). Our data support this hypothesis, as our patients with larger anterior cingulate volumes reported greater psychotic symptom improvement overtime (McCormick et al., 2005). In addition, functional and structural imaging data found convergent abnormalities in the medial frontal cortex including the anterior cingulate (Fornito et al., 2009; Pomarol-Clotet et al., 2010).

Structural abnormalities have also been revealed in thalamic nuclei and their projections in schizophrenia (Andreasen et al., 1994; Magnotta et al., 2008). Specifically, the thalamus has been shown to be reduced in size in schizophrenia (Andreasen et al., 1994; Buschman and Miller, 2007). In addition, FA was decreased in the internal capsule connecting the thalamus to the anterior cingulate (Oh et al., 2009). DTI reveals reduced FA in the white matter fiber tracts located between the thalamus and cerebellum in patients with schizophrenia compared to normal controls. Specifically, there was reduced FA within the superior cerebellar peduncle but not along the tract from the cerebellum to the thalamus (Magnotta et al., 2008). Little is known about whether the thalamus is essentially involved in schizophrenia or whether it is simply a convergence point and relay station for signals from other parts of the brain (Saalmann and Kastner, 2011). However, medial thalamic nuclei have been shown to project to the anterior cingulate cortex and inactivating these projections impairs working memory (Hsu and Shyu, 1997; Parnaudeau et al., 2013).

We have also reported that our schizophrenia patients have decreased overall cerebellar volume and, more specifically, decreased volume of the anterior lobe of the cerebellar vermis. Decreased cerebellar volume correlated with longer duration of psychotic and negative symptoms, and greater psychosocial impairment (Nopoulos et al., 1999; Wassink et al., 1999). Post mortem morphometric analyses of patients with schizophrenia confirm decreased anterior cerebellar vermis volume (Weinberger et al., 1980). A reduction of gray matter in Crus I and II of lobule VII has also been reported (Kühn et al., 2012). There may also be reduced FA in the vermis and middle cerebellar peduncles of schizophrenia patients (Okugawa et al., 2003, 2005).

Human lesion studies provide support for cingulocerebellar involvement in cognition. Although cerebellar lesions predominantly reveal motor impairments (Groiss and Ugawa, 2013), patients also suffer from comorbid cognitive impairments (Gottwald et al., 2004; Grimaldi and Manto, 2012). These dysfunctions include impaired timing, attention, memory, and language, all of which classically rely on the frontal lobes (Akshoomoff and Courchesne, 1992; Fiez et al., 1992; Grafman et al., 1992; Courchesne et al., 1994; Stoodley and Schmahmann, 2009). Schmahmann's cerebellar cognitive affective syndrome has shown that human cerebellar lesions cause cognitive impairments (Schmahmann, 2004). Inducing transient impairments using repetitive transcranial cerebellar stimulation has recently been shown to impair cognitive tasks such as language, emotion, learning, memory, perception, and timing (Fierro et al., 2007; Koch et al., 2007; Oliveri et al., 2007; Grube et al., 2010; Bijsterbosch et al., 2011; Boehringer et al., 2013; Tomlinson et al., 2013; Grimaldi et al., 2014). Similar deficits are reported following lesions to the anterior cingulate (Devinsky et al., 1995). Specifically, timing on the go-nogo task, which probes response inhibition, has been shown to be impaired (Picton et al., 2006). 


\section{ANATOMICAL CONNECTIONS}

Neuronal tract-tracing has made giant strides to link the cerebellum to prefrontal networks, but many have focused exclusively on the dorsal lateral prefrontal cortex, which rodents lack (Uylings et al., 2003). The dorsal lateral prefrontal cortex (Brodmann Areas 9/46) has been the subject of extensive tracing studies in primates, which establish a "closed-loop" linking cerebellar nuclei (specifically the dentate) and the dorsal lateral prefrontal cortex via the contralateral thalamus. Retrograde tracer infusions in the dorsolateral prefrontal cortex and DTI reveal projections back to the deep cerebellar nuclei and cerebellar cortex via the pontine nuclei (PN; Middleton and Strick, 2001; Kamali et al., 2010; Schulz et al., 2014; Figure 2). These studies establish the potential for cerebellar-prefrontal interactions in primates but additional research is necessary (Uylings et al., 2003).

As we have argued, the anterior cingulate cortex is essential for normal cognition and shows impairments in schizophrenia. In humans, the anterior cingulate is also known as Brodmann areas $24 / 32$ or the prelimbic cortices. Although homogenous in rodents, nomenclature is inconsistent. In rodents, the anterior cingulate cortex (Cg3/prelimbic) is commonly known as the medial prefrontal cortex and is described based on four cytoarchitecturally unique regions, $\mathrm{Cg} 1, \mathrm{Cg} 2, \mathrm{Cg} 3 /$ prelimbic, and infralimbic (Bostan et al., 2013; Vogt et al., 2013; Vogt and Paxinos, 2014). Although it remains unclear if a similar "closed-loop" exists in the cingulocerebellar circuit, we hope to elucidate these connections.

The cerebellar afferent pathway in the cingulocerebellar circuit involves direct anterior cingulate projections to the PN (Vilensky and Van Hoesen, 1981; Glickstein et al., 1985; Legg et al., 1989; Dembrow et al., 2010). Specifically, Vilensky et al. report that the rostral cingulate projects to the medial PN while the caudal cingulate regions project more laterally (Vilensky and Van Hoesen, 1981). These corticopontine fibers form the middle cerebellar peduncle and project to the deep cerebellar nuclei and cerebellar cortex.

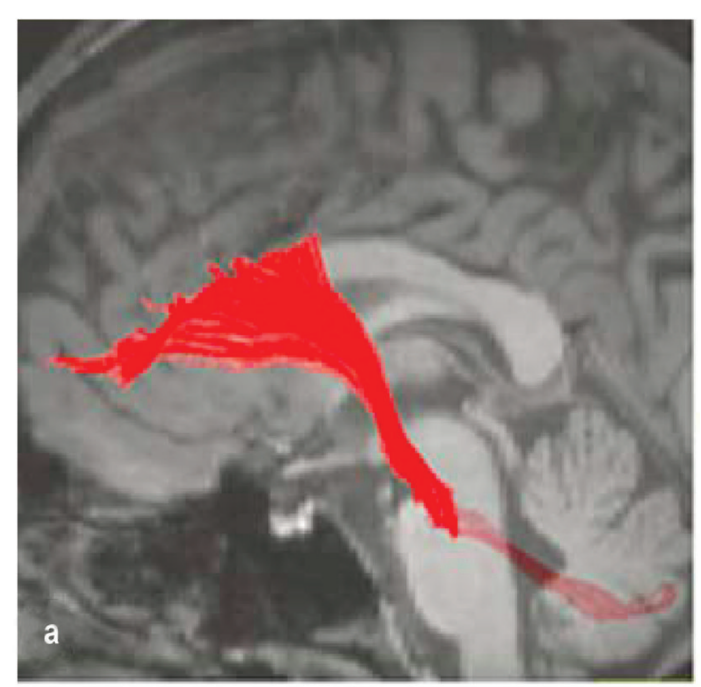

FIGURE 2 | Fronto-ponto-cerebellar tractography reconstructed on a 3D T1- weighted image (Kamali et al., 2010).
There is evidence for two efferent pathways through which deep cerebellar nuclei communicate with the anterior cingulate. The first efferent pathway involves a disynaptic connection between the deep cerebellar nuclei and contralateral thalamus (Magnotta et al., 2008; Strick et al., 2009). Medial thalamic nuclei have been shown to project to the anterior cingulate cortex (Hsu and Shyu, 1997; Parnaudeau et al., 2013) although there is evidence for projections from all thalamic nuclei depending on the precise location of the anterior cingulate/prelimbic area in question (Condé et al., 1990). Therefore, it is likely that cerebellar projections to the thalamus are capable of transmitting information to broad regions of the anterior cingulate cortex. These connections are highly topographic and the labeled neurons are highly dependent on the precise location of the tracer injection.

The second efferent pathway includes deep cerebellar nuclei (fastigial) projections to the VTA (Snider et al., 1976). The VTA is known to supply dopaminergic input to the anterior cingulate and is able to affect neuronal activity when pharmacologically manipulated (Williams and Goldman-Rakic, 1998). Studies have corroborated this efferent pathway by showing that electrically stimulating cerebellar dentate nuclei (DN; Mittleman et al., 2008) and fastigial nuclei (FN; Watson et al., 2009) influences medial prefrontal dopamine signaling, which is impaired in schizophrenia (Hadley et al., 2014). Conversely, electrically stimulating the medial prefrontal cortex elicited neuronal firing in cerebellar lobule VII which projects back to the deep nuclei (Watson et al., 2009). A similar pathway and mechanistic approach to target the dento-VTA-PFC tract has been suggested by Rogers et al. in autism (Rogers et al., 2013) (see section on applications for neuropsychiatric illnesses). One challenge of electrical stimulation in mapping these circuits is that the influence of fibers of passage and indirect stimulation of neighboring nuclei confounds the results. Future studies using optogenetics may achieve greater specificity.

Although these studies show connections exist, the precise projections remain elusive. To illuminate the cingulocerebellar circuit, we infused retrograde tracer (RetroBeads, Lumaflour) in the left anterior cingulate/medial frontal cortex and anterograde tracer (Phaseolus vulgaris leucoagglutinin, Life Technologies) in the right cerebellar dentate deep nuclei of Long Evans rats and found these structures to be disynaptically connected via two distinct routes as previously reported. Single synapse red prefrontal beads and green cerebellar tracer colocalized on left ventrolateral thalamic nuclei and on VTA neurons nuclei (Figures 3A,B). Convergence of information in these networks provides two avenues through which the cerebellum may influence neurons in the anterior cingulate cortex. However, the cerebellum may influence cortical function indirectly through other thalamic inputs. More analyses are needed to identify or rule out colocalization in other thalamic nuclei.

This anatomical connection opens up an avenue for the cerebellum to modulate aberrant prefrontal networks in schizophrenia. We are currently analyzing longitudinal DTI and tractography data from patients at intake and throughout the disease course, which will allow us to choose regions of interest in the anterior cingulate and the deep cerebellar nuclei to more precisely document abnormalities in the cingulocerebellar circuit. 


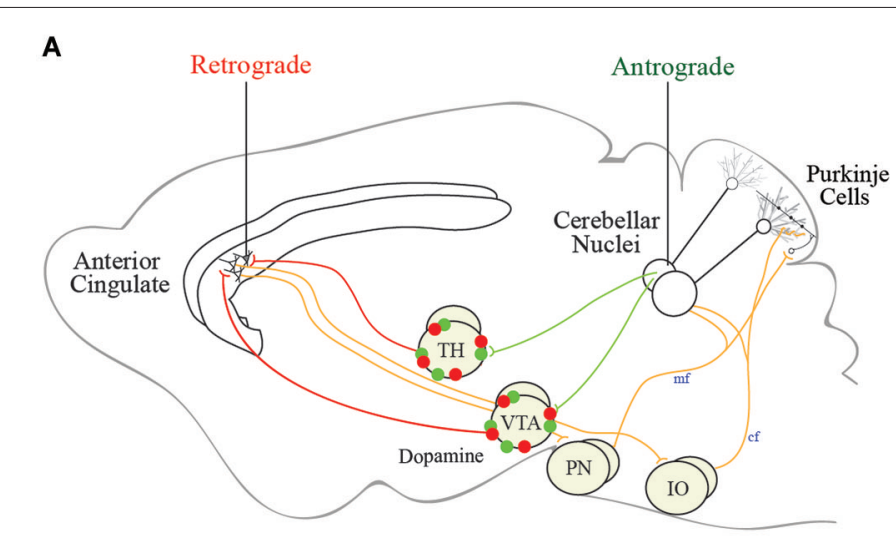

B

FIGURE 3 | Proposed efferent cingulocerellar circuitry. (A) Schematic representation of the efferent cerebellar projections enabling cerebellar access to the medial prefrontal cortex/anterior cingulate via the ventrolateral thalamus and VTA. Two efferent pathways are thought to connect the cerebellum and prefrontal cortex (1) Cerebellar projections originating from dentate (DN) or fastigial nuclei (FN) to the contralateral thalamus and anterior cingulate cortex; and (2) Cerebellar projections originating from DN or FN to the contralateral

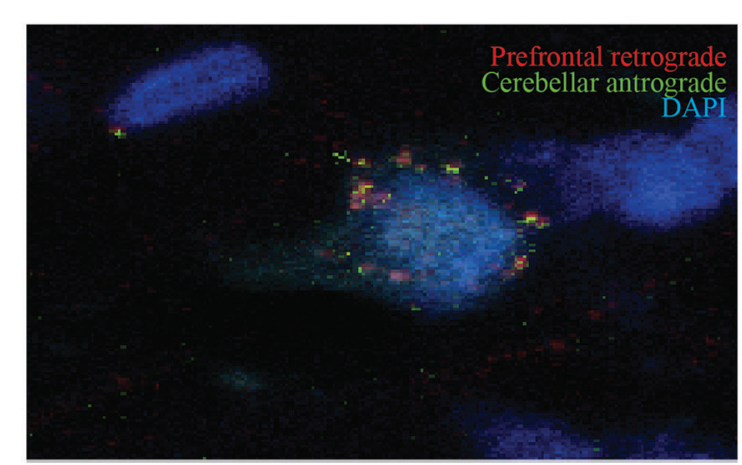

ventral tegmental area (VTA) which send dopaminergic projections to the anterior cingulate cortex. The afferent pathways from the anterior cingulate back to the cerebellum via the pontine nuclei (PN) and inferior olive (IO). (B) Our tract tracing data following anterograde tracer (green) in the right dentate nuclei and retrograde tracer (red) in the contralateral (left) medial prefrontal cortex revealed tracer colocalization of both red and green beads on a single contralateral ventrolateral thalamic (VLTh) neuron (B).
It is important to note that as deep cerebellar nuclei are the sole output of the cerebellum, abnormalities in any area of the cerebellum have the potential to influence frontal function through the cinglocerebellar circuit.

\section{A testable hypothesis: cerebellar stimulation restores prefrontal function and rescues cognition in schizophrenia}

It is through the convergence of cerebellar deep nuclei and anterior cingulate projections on thalamic neurons that we propose the cerebellum can be harnessed to rescue aberrant prefrontal circuits in schizophrenia. The implications of this efferent, disynaptic pathway are numerous. Cerebellar stimulation may have the ability to restore prefrontal neuronal activity and firing patterns, allowing relief from some of the cognitive symptoms of schizophrenia.

Several studies provide support for the efficacy of cerebellar stimulation in neuropsychiatry (Grimaldi et al., 2014). A classic study electrically stimulated the cerebellum and reported improved cognition based on increased alertness, improvement in thinking, and fluency of speech in addition to many enriched emotional characteristics in patients with epilepsy (Cooper et al., 1976). Recently, cerebellar vermal TBS has been effective at relieving some cognitive symptoms in treatment-resistant schizophrenia patients (Demirtas-Tatlidede et al., 2010). In addition, Schutter et al. showed that cerebellar vermal TBS produced downstream changes in neuronal activity in the frontal cortex (Schutter et al., 2003). The exact cerebellar circuitry needs to be explicitly mapped prior to pursuing translational research.

How the cerebellum normally influences the prefrontal cortex and anterior cingulate is an important question that can be investigated using neuronal ensemble recordings of these areas in animals exhibiting phenotypes of schizophrenia. The cingulocerebellar circuit is likely essential for a variety of cognitive tasks as is documented by the previously described neuroimaging results. Correlating neuronal recordings will provide clarity as to how the cerebellum and prefrontal cortex work in synchrony during cognitive tasks such as learning, timing, and attention. Task-specific modulation will indicate if these areas are necessary.

Several groups have made progress deciphering the role of nodes in the cingulocerebellar circuit using electrical stimulation (Mittleman et al., 2008; Watson et al., 2009; Rogers et al., 2011, 2013). However, results from these studies are limited due to the unwanted spread of electrical stimulation. To circumvent this issue, we propose using optogenetic stimulation of select, isolated pools of neurons in the cingulocerebellar circuit. Optogenetic stimulation of Purkinje cells has been shown to be an effective way to modulate cerebellar output (Tsubota et al., 2011). Using our tract-tracing results to target specific deep nuclear projections in the cingluocerebellar circuit, channelrhodopsin, a light-activated channel, can be infused into cerebellar neurons. Once expressed, these proteins render their projections photoexcitable. Optical fibers can be placed in the thalamus to selectively stimulate the cerebellar neuronal projections to the anterior cingulate while not affecting other cerebellar neuronal populations. Optogenetically stimulating cerebellar dentate projections in the thalamus could influence the prefrontal cortex (Figure 4). This optogenetic paradigm could be combined with neuronal ensemble recordings to probe the dynamic relationship between the prefrontal cortex and cerebellum while analyzing task-dependent modulation. Based on evidence from cerebellar stimulation studies, cerebellar optogenetic stimulation has the potential to enhance prefrontal neuronal modulation and show correlates of behavioral improvement.

Another way to investigate the cingulocerebellar circuit is to induce abnormalities similar to those reported during schizophrenia and attempt to rescue impairments using cerebellar stimulation. Targeting neurotransmitter cascades such as 


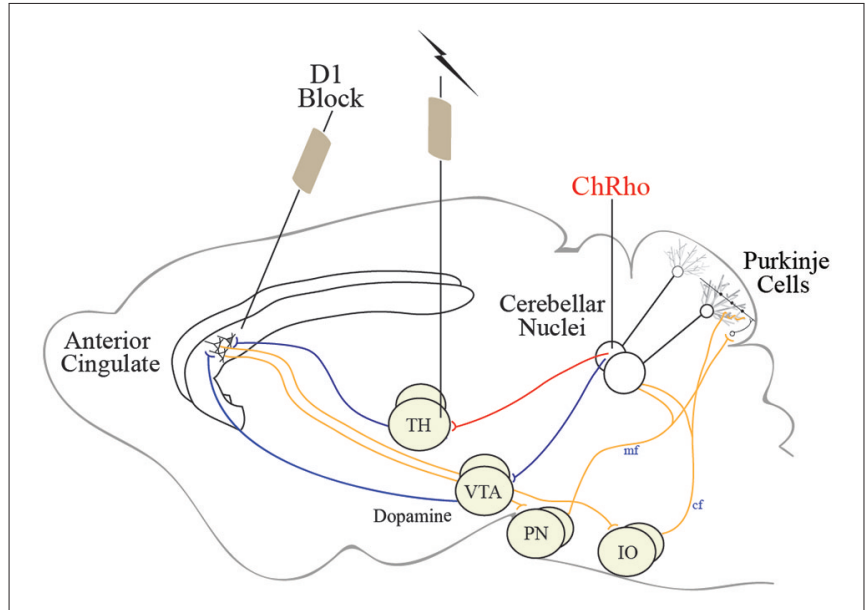

FIGURE 4 | Schematic representation of the cingulocerebellar pathways allowing the cerebellum access to the prefrontal cortex. We propose using optogenetic stimulation of cerebellar projection neurons in the thalamus to recover activity in aberrant prefrontal neuronal ensembles in schizophrenia. Channelrhodopsin, a light-activated channel, can be infused into cerebellar neurons rendering cerebellar projections photoexcitable. Stimulating thalamic (or VTA) optical fibers can selectively stimulate the cerebellar neuronal projections to the anterior cingulate while not affecting other cerebellar neuronal populations. This optogenetic paradigm can be used in animals exhibiting phenotypes of schizophrenia and other neuropsychiatric illnesses in combination with elementary cognitive tasks impaired in schizophrenia to recover cognitive function and probe the cingluocerebellar circuit.

dopamine (Abi-Dargham et al., 2002; Goldman-Rakic et al., 2004), glutamate (Olney and Farber, 1995; Chaki and Hikichi, 2011; Moghaddam and Javitt, 2012; Anticevic et al., 2013), and GABA in prefrontal pyramidal neurons, it is possible to mimic schizophrenia phenotypes by direct pharmacological microinjections (Jones et al., 2011). These manipulations may induce changes in neuronal activity that resemble abnormalities in schizophrenia and can be correlated with behavioral abnormalities. For example, frontal dopamine has been implicated in schizophrenia (Abi-Dargham et al., 2002; Goldman-Rakic et al., 2004; Stahl and Buckley, 2007). The level of frontal dopamine determines the type and severity of associated symptoms (Goldman-Rakic et al., 2004; Kuepper et al., 2012). Excess dopamine contributes to positive symptoms such as hallucinations and delusions, while depleted dopamine is responsible for negative symptoms such as anhedonia, avolition, and cognitive deficits such as impaired timing (Andreasen and Olsen, 1982; Seeman, 1987; Kuepper et al., 2012).

We, and others, have shown that temporal processing depends on the cerebellum for short, sub-second intervals (Ivry and Spencer, 2004; Buhusi and Meck, 2005; Bracha et al., 2009; Parker et al., 2009) while D1 dopamine signaling in the anterior cingulate of the prefrontal cortex is essential for longer intervals (Deutch, 1993; Narayanan et al., 2012; Parker et al., 2013a,c). In schizophrenia, the prefrontal cortex shows abnormal D1 dopamine (Weinberger et al., 1986; Okubo et al., 1997; Goldman-Rakic et al., 2004) and patients inaccurately estimate a discrete interval of time (Elvevåg et al., 2003; Bonnot et al.,
2011). In animals, it is possible to model these concepts by locally infusing pharmacological agents into the frontal cortex to disrupt prefrontal D1 dopamine signaling and mimic impaired timing (Narayanan et al., 2012). If the cingulocerebellar circuit is necessary for temporal processing and is sensitive to levels of prefrontal dopamine, pharmacologically manipulating prefrontal dopamine will disrupt neuronal activity and impair timing. Mittleman et al. report efflux of dopamine in the prelimibic cortex (anterior cingulate) following electrical stimulation of the dentate nuclei (Mittleman et al., 2008). Therefore, optogenetically stimulating cerebellar nuclei has the potential to rescue aberrant contralateral prefrontal neuronal ensembles, recovering elementary cognitive tasks (Boyden et al., 2005; Narayanan et al., 2012).

An example of a task that has been used to probe the role of the cingulocerebellar circuit is eyeblink conditioning as it is abnormal in schizophrenia (Brown et al., 2005; Bolbecker et al., 2009; Forsyth et al., 2012; Parker et al., 2013b). Specifically, trace eyeblink conditioning, where a conditioning stimulus and an unconditioned stimulus are separated by a trace interval, requires integration of the cerebellum and frontal cortex (Weiss and Disterhoft, 1996). Siegel et al. have explored this afferent pathway and the influence of the dorsal anterior cingulate in layers V and VII (secondary motor cortices) in rabbits (Siegel et al., 2012). They found direct projections to the ipsilateral rostral $\mathrm{PN}$ via the corticospinal pyramidal tract. It has also been reported that prefrontal neurons are consistently active in the trace interstimulus interval, likely encoding the elapsed time between the stimulus and providing the cerebellum with the timing information necessary to accurately execute the eyeblink response (Siegel et al., 2012; Chen et al., 2014). It is possible to pharmacologically mimic psychiatric abnormalities by inactivating various areas of the prefrontal cortex to produce disruptions in trace eyeblink conditioning. Following expression of channelrhodopsin infusions in deep cerebellar nuclei, optogenetic stimulation of cerebellar projections to the thalamus have the potential to recover prefrontal neuronal activity and rescue eyeblink conditioning.

Optogenetic stimulation of the cingulocerebellar pathway can also be explored in genetically modified animals exhibiting schizophrenia phenotypes. Currently, several animals exist that exhibit some phenotypes of schizophrenia such as G72/G30, Df(16)A KO model, and Disrupted in Schizophrenia 1 (DISC1; Shevelkin et al., 2014). Each of these animals has cerebellar abnormalities similar to those consistently detected in schizophrenia making them ideal models to study the cingulocerebellar circuit (Shevelkin et al., 2014).

There are many additional aspects of this circuit that can be explored. Although we have focused on a very specific circuit involving the anterior cingulate and cerebellum, it is possible that a more widespread activity is sufficient for normal functioning. There are known connections throughout frontal lobes and normalized neuronal firing throughout the brain may prove essential rather than the firing patterns of one particular structure. This theory is supported by the more diffuse type of stimulation used by transcranial magnetic stimulation (Grimaldi et al., 2014) and thalamic stimulation (Klein et al., 2013). 


\section{CEREBELLAR STIMULATION IN PARKINSON'S DISEASE AND AUTISM}

Although schizophrenia is not considered to be a motor disease, many indicators of motor dysfunction are present, suggesting that the basic abnormality in the disorder could be a brain system that mediates both motor and cognitive functions. Kraepelin described a variety of motor abnormalities in schizophrenia in his classic textbook (1919). Slowed reaction time is one of the oldest and most robust tests showing differences between schizophrenic patients and normal controls. More recent studies of premorbid indicators and neurological soft signs also implicate the motor system (Walker and Shaye, 1982; Gupta et al., 1995; Flashman et al., 1996; Mouchet-Mages et al., 2011). These mild indicators of poor coordination provide a clue that the underlying mechanism may reflect an abnormality in a basic process that regulates the synchrony of both thought and motor activity. Therefore, schizophrenia may be conceptualized as a disease that is characterized by poor coordination, or dysmetria, in all domains of functioning, including movement and cognition. In addition to its role in cognition, the cerebellum has traditionally been associated with movement and gait. Therefore, the circuit between the prefrontal cortex and cerebellum may facilitate the smooth execution, or synchrony of both motor and cognitive function. As we have proposed optogenetic stimulation of cerebellar projections for the treatment of the cognitive symptoms of schizophrenia, the motor impairments may actually benefit as well.

Parkinson's disease (PD) also causes impaired gait and cognition and involves abnormalities in the cerebellum, prefrontal cortex, and the basal ganglia. Cerebellar circuitry involves efferent connections with the basal ganglia which project back to the cerebellum via the PN (similar to the anterior cingulate projections) (Bostan and Strick, 2010; Bostan et al., 2010). However, similar to schizophrenia, the role of the cerebellum in PD is unknown. Recently, Wu et al. published a thorough review of the role of the cerebellum in PD (Wu and Hallett, 2013). They speculated that the cerebellum plays either a compensatory role or a pathological role (Wu and Hallett, 2013). Using optogenetic stimulation of cerebellar projections in the striatum, it may be possible to modulate cerebellar activity and repair movement, gait, and cognition in PD patients. How cerebellar circuitry interacts with the anterior cingulate via the dopaminergic VTA projections should be pursued, as cerebellar stimulation could represent novel therapeutic opportunities for both the cognitive and motor impairments in PD.

Courchesne et al. have documented cerebellar abnormalities in autism. In addition to decrease in cerebellar vermal volume, there appears to be aberrancies in cerebellar-prefrontal interactions (Carper and Courchesne, 2000; Pierce and Courchesne, 2001; Courchesne et al., 2011). Recently, Purkinje cell abnormalities have been linked to behavioral deficits similar to those exhibited in autism (Sudarov, 2013). The middle cerebellar peduncle has also shown structural impairments in autism and as the output pathway for cerebellar projections, this altered microstructure could have dire consequences for cerebellar-frontal lobe communications (Sivaswamy et al., 2010; Hanaie et al., 2013). More research needs to be done to understand the behavioral and cognitive symptoms in autism which depend on the cingulocerebellar pathway (Heck and Howell, 2013). Using optogenetics, this circuit should be parsed out and pursued to repair brain circuitry in autism. There are currently several animal models that exhibit phenotypes of autism, which are ripe for investigation.

\section{CONCLUSIONS}

The ideas described here have the potential to map the influence of cerebellar circuitry on the frontal cortex and lead to new insights about cingulocerebellar interactions. Through the cingulocerebellar circuit, cerebellar stimulation may recover aberrancies in the anterior cingulate cortex, rescuing cognition in schizophrenia. To our knowledge, this idea has not been proposed before, and we hope systematically applying the techniques described here to the many cognitive tasks impaired in schizophrenia such as attention and working memory, will encourage the development of new, targeted treatments for treatment-resistant patients.

\section{ACKNOWLEDGMENTS}

Grand funding was provided by Brain \& Behavior Research Foundation NARSAD grant, Lieber Investigators, and Nellie Ball Trust Research Grant.

\section{REFERENCES}

Abi-Dargham, A., Mawlawi, O., Lombardo, I., Gil, R., Martinez, D., Huang, Y., et al. (2002). Prefrontal dopamine D1 receptors and working memory in schizophrenia. J. Neurosci. 22, 3708-3719.

Adams, R., and David, A. S. (2007). Patterns of anterior cingulate activation in schizophrenia: a selective review. Neuropsychiatr. Dis. Treat. 3, 87-101. doi: 10. 2147/nedt.2007.3.1.87

Akshoomoff, N. A., and Courchesne, E. (1992). A new role for the cerebellum in cognitive operations. Behav. Neurosci. 106, 731-738. doi: 10.1037/0735-7044. 106.5.731

Alphs, L. (2006). An industry perspective on the NIMH consensus statement on negative symptoms. Schizophr. Bull. 32, 225-230. doi: 10.1093/schbul/sbj056

Andreasen, N. C., Arndt, S., Swayze, V. 2nd, Cizadlo, T., Flaum, M., O’Leary, D., et al. (1994). Thalamic abnormalities in schizophrenia visualized through magnetic resonance image averaging. Science 266, 294-298. doi: 10.1126/science. 7939669

Andreasen, N. C., O’Leary, D. S., Arndt, S., Cizadlo, T., Rezai, K., Watkins, G. L., et al. (1995a). I. PET studies of memory: novel and practiced free recall of complex narratives. Neuroimage 2, 284-295. doi: 10.1006/nimg.1995.1036

Andreasen, N. C., O'Leary, D. S., Cizadlo, T., Arndt, S., Rezai, K., Watkins, G. L., et al. (1995b). II. PET studies of memory: novel versus practiced free recall of word lists. Neuroimage 2, 296-305. doi: 10.1006/nimg.1995.1037

Andreasen, N. C., O’Leary, D. S., Flaum, M., Nopoulos, P., Watkins, G. L., Boles Ponto, L. L., et al. (1997). Hypofrontality in schizophrenia: distributed dysfunctional circuits in neuroleptic-naïve patients. Lancet 349, 1730-1734. doi: 10. 1016/s0140-6736(96)08258-x

Andreasen, N. C., O’Leary, D. S., Paradiso, S., Cizadlo, T., Arndt, S., Watkins, G. L., et al. (1999). The cerebellum plays a role in conscious episodic memory retrieval. Hum. Brain Mapp. 8, 226-234. doi: 10.1002/(sici)1097-0193(1999)8:4<226::aidhbm6>3.0.co; $2-4$

Andreasen, N. C., and Olsen, S. (1982). Negative v positive schizophrenia: definition and validation. Arch. Gen. Psychiatry 39, 789-794. doi: 10.1001/archpsyc. 1982.04290070025006

Andreasen, N. C., Paradiso, S., and O’Leary, D. S. (1998). "Cognitive Dysmetria” as an integrative theory of schizophrenia. Schizophr. Bull. 24, 203-218. doi: 10. 1093/oxfordjournals.schbul.a033321

Andreasen, N. C., and Pierson, R. (2008). The role of the cerebellum in schizophrenia. Biol. Psychiatry 64, 81-88. doi: 10.1016/j.biopsych.2008.01.003

Anticevic, A., Cole, M. W., Repovs, G., Savic, A., Driesen, N. R., Yang, G., et al. (2013). Connectivity, pharmacology and computation: toward a mechanistic understanding of neural system dysfunction in schizophrenia. Front. Psychiatry 4:169. doi: 10.3389/fpsyt.2013.00169 
Artiges, E., Salamé, P., Recasens, C., Poline, J. B., Attar-Levy, D., De La Raillère, A., et al. (2000). Working memory control in patients with schizophrenia: a PET study during a random number generation task. Am. J. Psychiatry 157, 15171519. doi: 10.1176/appi.ajp.157.9.1517

Bijsterbosch, J. D., Lee, K.-H., Hunter, M. D., Tsoi, D. T., Lankappa, S., Wilkinson, I. D., et al. (2011). The role of the cerebellum in sub- and supraliminal error correction during sensorimotor synchronization: evidence from fMRI and TMS. J. Cogn. Neurosci. 23, 1100-1112. doi: 10.1162/jocn.2010.21506

Boehringer, A., Macher, K., Dukart, J., Villringer, A., and Pleger, B. (2013). Cerebellar transcranial direct current stimulation modulates verbal working memory. Brain Stimul. 6, 649-653. doi: 10.1016/j.brs.2012.10.001

Bolbecker, A. R., Mehta, C. S., Edwards, C. R., Steinmetz, J. E., O’Donnell, B. F., and Hetrick, W. P. (2009). Eye-blink conditioning deficits indicate temporal processing abnormalities in schizophrenia. Schizophr. Res. 111, 182-191. doi: 10. 1016/j.schres.2009.03.016

Bonnot, O., de Montalembert, M., Kermarrec, S., Botbol, M., Walter, M., and Coulon, N. (2011). Are impairments of time perception in schizophrenia a neglected phenomenon? J. Physiol. Paris 105, 164-169. doi: 10.1016/j.jphysparis. 2011.07.006

Bostan, A. C., Dum, R. P., and Strick, P. L. (2010). The basal ganglia communicate with the cerebellum. Proc. Natl. Acad. Sci. U S A 107, 8452-8456. doi: 10. 1073/pnas.1000496107

Bostan, A. C., Dum, R. P., and Strick, P. L. (2013). Cerebellar networks with the cerebral cortex and basal ganglia. Trends Cogn. Sci. 17, 241-254. doi: 10.1016/j. tics.2013.03.003

Bostan, A. C., and Strick, P. L. (2010). The cerebellum and basal ganglia are interconnected. Neuropsychol. Rev. 20, 261-270. doi: 10.1007/s11065-0109143-9

Boyden, E. S., Zhang, F., Bamberg, E., Nagel, G., and Deisseroth, K. (2005). Millisecond-timescale, genetically targeted optical control of neural activity. Nat. Neurosci. 8, 1263-1268. doi: 10.1038/nn1525

Bracha, V., Zbarska, S., Parker, K., Carrel, A., Zenitsky, G., and Bloedel, J. R. (2009). The cerebellum and eye-blink conditioning: learning versus network performance hypotheses. Neuroscience 162, 787-796. doi: 10.1016/j.neuroscience. 2008.12.042

Brown, S. M., Kieffaber, P. D., Carroll, C. A., Vohs, J. L., Tracy, J. A., Shekhar, A., et al. (2005). Eyeblink conditioning deficits indicate timing and cerebellar abnormalities in schizophrenia. Brain Cogn. 58, 94-108. doi: 10.1016/j.bandc. 2004.09.011

Buhusi, C. V., and Meck, W. H. (2005). What makes us tick? Functional and neural mechanisms of interval timing. Nat. Rev. Neurosci. 6, 755-765. doi: 10. 1038/nrn1764

Buschman, T. J., and Miller, E. K. (2007). Top-down versus bottom-up control of attention in the prefrontal and posterior parietal cortices. Science 315, 18601862. doi: 10.1126/science. 1138071

Carper, R. A., and Courchesne, E. (2000). Inverse correlation between frontal lobe and cerebellum sizes in children with autism. Brain 123(Pt. 4), 836-844. doi: 10. 1093/brain/123.4.836

Carroll, C. A., O’Donnell, B. F., Shekhar, A., and Hetrick, W. P. (2009). Timing dysfunctions in schizophrenia as measured by a repetitive finger tapping task. Brain Cogn. 71, 345-353. doi: 10.1016/j.bandc.2009.06.009

Carter, C. S., Braver, T. S., Barch, D. M., Botvinick, M. M., Noll, D., and Cohen, J. D. (1998). Anterior cingulate cortex, error detection and the online monitoring of performance. Science 280, 747-749. doi: 10.1126/science.280.5364.747

Carter, C. S., MacDonald, A. W. 3rd, Ross, L. L., and Stenger, V. A. (2001). Anterior cingulate cortex activity and impaired self-monitoring of performance in patients with schizophrenia: an event-related fMRI study. Am. J. Psychiatry 158, 1423-1428. doi: 10.1176/appi.ajp.158.9.1423

Cavanagh, J. F., Cohen, M. X., and Allen, J. J. B. (2009). Prelude to and resolution of an error: EEG phase synchrony reveals cognitive control dynamics during action monitoring. J. Neurosci. 29, 98-105. doi: 10.1523/jneurosci.4137-08.2009

Chaki, S., and Hikichi, H. (2011). Targeting of metabotropic glutamate receptors for the treatment of schizophrenia. Curr. Pharm. Des. 17, 94-102. doi: 10. 2174/138161211795049570

Chen, H., Yang, L., Xu, Y., Wu, G., Yao, J., Zhang, J., et al. (2014). Prefrontal control of cerebellum-dependent associative motor learning. Cerebellum 13, 6478. doi: 10.1007/s12311-013-0517-4

Condé, F., Audinat, E., Maire-Lepoivre, E., and Crépel, F. (1990). Afferent connections of the medial frontal cortex of the rat. A study using retrograde transport of fluorescent dyes. I. Thalamic afferents. Brain Res. Bull. 24, 341-354. doi: 10. 1016/0361-9230(90)90088-h

Cooper, I. S., Amin, I., Riklan, M., Waltz, J. M., and Poon, T. P. (1976). Chronic cerebellar stimulation in epilepsy. Clinical and anatomical studies. Arch. Neurol. 33, 559-570. doi: 10.1001/archneur.1976.00500080037006

Courchesne, E., Mouton, P. R., Calhoun, M. E., Semendeferi, K., Ahrens-Barbeau, C., Hallet, M. J., et al. (2011). Neuron number and size in prefrontal cortex of children with autism. JAMA 306, 2001-2010. doi: 10.1001/jama.2011. 1638

Courchesne, E., Townsend, J., Akshoomoff, N. A., Saitoh, O., Yeung-Courchesne, R., Lincoln, A. J., et al. (1994). Impairment in shifting attention in autistic and cerebellar patients. Behav. Neurosci. 108, 848-865. doi: 10.1037/0735-7044.108. 5.848

Crespo-Facorro, B., Paradiso, S., Andreasen, N. C., O'Leary, D. S., Watkins, G. L., Boles Ponto, L. L., et al. (1999). Recalling word lists reveals "cognitive dysmetria" in schizophrenia: a positron emission tomography study. Am. J. Psychiatry 156, 386-392.

Crespo-Facorro, B., Wiser, A. K., Andreasen, N. C., O'Leary, D. S., Watkins, G. L., Boles Ponto, L. L., et al. (2001). Neural basis of novel and well-learned recognition memory in schizophrenia: a positron emission tomography study. Hum. Brain Mapp. 12, 219-231. doi: 10.1002/1097-0193(200104)12:4<219::aidhbm1017>3.0.co;2-1

Dembrow, N. C., Chitwood, R. A., and Johnston, D. (2010). Projection-specific neuromodulation of medial prefrontal cortex neurons. J. Neurosci. 30, 1692216937. doi: 10.1523/jneurosci.3644-10.2010

Demirtas-Tatlidede, A., Freitas, C., Cromer, J. R., Safar, L., Ongur, D., Stone, W. S., et al. (2010). Safety and proof of principle study of cerebellar vermal theta burst stimulation in refractory schizophrenia. Schizophr. Res. 124, 91-100. doi: 10. 1016/j.schres.2010.08.015

Demirtas-Tatlidede, A., Vahabzadeh-Hagh, A. M., and Pascual-Leone, A. (2013). Can noninvasive brain stimulation enhance cognition in neuropsychiatric disorders? Neuropharmacology 64, 566-578. doi: 10.1016/j.neuropharm.2012. 06.020

Deutch, A. Y. (1993). Prefrontal cortical dopamine systems and the elaboration of functional corticostriatal circuits: implications for schizophrenia and Parkinson's disease. J. Neural Transm. Gen. Sect. 91, 197-221. doi: 10.1007/bf012 45232

Devinsky, O., Morrell, M. J., and Vogt, B. A. (1995). Contributions of anterior cingulate cortex to behaviour. Brain 118(Pt. 1), 279-306. doi: 10.1093/brain/118.1. 279

Elvevåg, B., McCormack, T., Gilbert, A., Brown, G. D. A., Weinberger, D. R., and Goldberg, T. E. (2003). Duration judgements in patients with schizophrenia. Psychol. Med. 33, 1249-1261. doi: 10.1017/s0033291703008122

Fierro, B., Palermo, A., Puma, A., Francolini, M., Panetta, M. L., Daniele, O., et al. (2007). Role of the cerebellum in time perception: a TMS study in normal subjects. J. Neurol. Sci. 263, 107-112. doi: 10.1016/j.jns.2007.06.033

Fiez, J. A., Petersen, S. E., Cheney, M. K., and Raichle, M. E. (1992). Impaired nonmotor learning and error detection associated with cerebellar damage. A single case study. Brain 115(Pt. 1), 155-178. doi: 10.1093/brain/115.1.155

Flashman, L. A., Flaum, M., Gupta, S., and Andreasen, N. C. (1996). Soft signs and neuropsychological performance in schizophrenia. Am. J. Psychiatry 153, 526532.

Fornito, A., Yücel, M., Dean, B., Wood, S. J., and Pantelis, C. (2009). Anatomical abnormalities of the anterior cingulate cortex in schizophrenia: bridging the gap between neuroimaging and neuropathology. Schizophr. Bull. 35, 973-993. doi: $10.1093 / \mathrm{schbul} / \mathrm{sbn} 025$

Forsyth, J. K., Bolbecker, A. R., Mehta, C. S., Klaunig, M. J., Steinmetz, J. E., O'Donnell, B. F., et al. (2012). Cerebellar-dependent eyeblink conditioning deficits in schizophrenia spectrum disorders. Schizophr. Bull. 38, 751-759. doi: 10.1093/schbul/sbQ128

Gasquoine, P. G. (2013). Localization of function in anterior cingulate cortex: from psychosurgery to functional neuroimaging. Neurosci. Biobehav. Rev. 37, 340348. doi: 10.1016/j.neubiorev.2013.01.002

Glahn, D. C., Laird, A. R., Ellison-Wright, I., Thelen, S. M., Robinson, J. L., Lancaster, J. L., et al. (2008). Meta-analysis of gray matter anomalies in schizophrenia: application of anatomic likelihood estimation and network analysis. Biol. Psychiatry 64, 774-781. doi: 10.1016/j.biopsych.2008.03.031

Glickstein, M., May, J. G. 3rd, and Mercier, B. E. (1985). Corticopontine projection in the macaque: the distribution of labelled cortical cells after large injections 
of horseradish peroxidase in the pontine nuclei. J. Comp. Neurol. 235, 343-359. doi: 10.1002/cne.902350306

Goldman-Rakic, P. S., Castner, S. A., Svensson, T. H., Siever, L. J., and Williams, G. V. (2004). Targeting the dopamine D1 receptor in schizophrenia: insights for cognitive dysfunction. Psychopharmacology (Berl) 174, 3-16. doi: 10. 1007/s00213-004-1793-y

Gottwald, B., Wilde, B., Mihajlovic, Z., and Mehdorn, H. M. (2004). Evidence for distinct cognitive deficits after focal cerebellar lesions. J. Neurol. Neurosurg. Psychiatry 75, 1524-1531. doi: 10.1136/jnnp.2003.018093

Grafman, J., Litvan, I., Massaquoi, S., Stewart, M., Sirigu, A., and Hallett, M. (1992). Cognitive planning deficit in patients with cerebellar atrophy. Neurology 42, 1493-1496. doi: 10.1212/wnl.42.8.1493

Grimaldi, G., Argyropoulos, G. P., Boehringer, A., Celnik, P., Edwards, M. J., Ferrucci, R., et al. (2014). Non-invasive cerebellar stimulation-a consensus paper. Cerebellum 13, 121-138. doi: 10.1007/s12311-013-0514-7

Grimaldi, G., and Manto, M. (2012). Topography of cerebellar deficits in humans. Cerebellum 11, 336-351. doi: 10.1007/s12311-011-0247-4

Groiss, S. J., and Ugawa, Y. (2013). "Chapter 51-Cerebellum," in Handbook of Clinical Neurology. Brain Stimulation, eds A. M. Lozano, M. Hallett (Elsevier), 643-653. Available online at: http://www.science direct.com/science/article/pii/B9780444534972000516. Accessed on February 21, 2014.

Grube, M., Lee, K.-H., Griffiths, T. D., Barker, A. T., and Woodruff, P. W. (2010). Transcranial magnetic theta-burst stimulation of the human cerebellum distinguishes absolute, duration-based from relative, beat-based perception of subsecond time intervals. Front. Psychol. 1:171. doi: 10.3389/fpsyg.2010. 00171

Gupta, S., Andreasen, N. C., Arndt, S., Flaum, M., Schultz, S. K., Hubbard, W. C., et al. (1995). Neurological soft signs in neuroleptic-naive and neuroleptictreated schizophrenic patients and in normal comparison subjects. Am. J. Psychiatry 152, 191-196.

Hadley, J. A., Nenert, R., Kraguljac, N. V., Bolding, M. S., White, D. M., Skidmore, F. M., et al. (2014). Ventral tegmental area/midbrain functional connectivity and response to antipsychotic medication in schizophrenia. Neuropsychopharmacology 39, 1020-1030. doi: 10.1038/npp.2013.305

Hanaie, R., Mohri, I., Kagitani-Shimono, K., Tachibana, M., Azuma, J., Matsuzaki, J., et al. (2013). Altered microstructural connectivity of the superior cerebellar peduncle is related to motor dysfunction in children with autistic spectrum disorders. Cerebellum 12, 645-656. doi: 10.1007/s12311-013-0475-x

Heck, D. H., and Howell, J. W. (2013). Prefrontal cortical-cerebellar interaction deficits in autism spectrum disorders. Autism S4:001. doi: 10.4172/2165-7890. S4-001

Honey, G. D., Pomarol-Clotet, E., Corlett, P. R., Honey, R. A. E., McKenna, P. J., Bullmore, E. T., et al. (2005). Functional dysconnectivity in schizophrenia associated with attentional modulation of motor function. Brain 128, 25972611. doi: 10.1093/brain/awh632

Hsu, M. M., and Shyu, B. C. (1997). Electrophysiological study of the connection between medial thalamus and anterior cingulate cortex in the rat. Neuroreport 8, 2701-2707. doi: 10.1097/00001756-199708180-00013

Ivry, R. B., and Spencer, R. M. (2004). Evaluating the role of the cerebellum in temporal processing: beware of the null hypothesis. Brain 127, E13-E14. doi: 10. 1093/brain/awh227

Jones, C., Watson, D., and Fone, K. (2011). Animal models of schizophrenia. Br. J. Pharmacol. 164, 1162-1194. doi: 10.1111/j.1476-5381.2011.01386.x

Kamali, A., Kramer, L. A., Frye, R. E., Butler, I. J., and Hasan, K. M. (2010). Diffusion tensor tractography of the human brain cortico-ponto-cerebellar pathways: a quantitative preliminary study. J. Magn. Reson. Imaging 32, 809817. doi: $10.1002 /$ jmri.22330

Klein, J., Hadar, R., Götz, T., Männer, A., Eberhardt, C., Baldassarri, J., et al. (2013). Mapping brain regions in which deep brain stimulation affects schizophrenialike behavior in two rat models of schizophrenia. Brain Stimul. 6, 490-499. doi: 10.1016/j.brs.2012.09.004

Koch, G., Oliveri, M., Torriero, S., Salerno, S., Lo Gerfo, E., and Caltagirone, C. (2007). Repetitive TMS of cerebellum interferes with millisecond time processing. Exp. Brain Res. 179, 291-299. doi: 10.1007/s00221-0060791-1

Koziol, L. F., Budding, D., Andreasen, N., D’Arrigo, S., Bulgheroni, S., Imamizu, H., et al. (2013). Consensus paper: the cerebellum's role in movement and cognition. Cerebellum 13, 151-177. doi: 10.1007/s12311-013-0511-x
Kuepper, R., Skinbjerg, M., and Abi-Dargham, A. (2012). The dopamine dysfunction in schizophrenia revisited: new insights into topography and course. Handb. Exp. Pharmacol. 212, 1-26. doi: 10.1007/978-3-642-25761-2_1

Kühn, S., Romanowski, A., Schubert, F., and Gallinat, J. (2012). Reduction of cerebellar grey matter in Crus I and II in schizophrenia. Brain Struct. Funct. 217, 523-529. doi: 10.1007/s00429-011-0365-2

Legg, C. R., Mercier, B., and Glickstein, M. (1989). Corticopontine projection in the rat: the distribution of labelled cortical cells after large injections of horseradish peroxidase in the pontine nuclei. J. Comp. Neurol. 286, 427-441. doi: $10.1002 / \mathrm{cne} .902860403$

Leiner, H. C., Leiner, A. L., and Dow, R. S. (1994). The underestimated cerebellum. Hum. Brain Mapp. 2, 244-254. doi: 10.1002/hbm.460020406

Magnotta, V. A., Adix, M. L., Caprahan, A., Lim, K., Gollub, R., and Andreasen, N. C. (2008). Investigating connectivity between the cerebellum and thalamus in schizophrenia using diffusion tensor tractography: a pilot study. Psychiatry Res. 163, 193-200. doi: 10.1016/j.pscychresns.2007.10.005

McCormick, L., Decker, L., Nopoulos, P., Ho, B.-C., and Andreasen, N. (2005). Effects of atypical and typical neuroleptics on anterior cingulate volume in schizophrenia. Schizophr. Res. 80, 73-84. doi: 10.1016/j.schres.2005. 06.022

Meyer-Lindenberg, A., Poline, J. B., Kohn, P. D., Holt, J. L., Egan, M. F., Weinberger, D. R., et al. (2001). Evidence for abnormal cortical functional connectivity during working memory in schizophrenia. Am. J. Psychiatry 158, 1809-1817. doi: 10.1176/appi.ajp.158.11.1809

Middleton, F. A., and Strick, P. L. (2001). Cerebellar projections to the prefrontal cortex of the primate. J. Neurosci. 21, 700-712.

Minzenberg, M. J., Laird, A. R., Thelen, S., Carter, C. S., and Glahn, D. C. (2009). Meta-analysis of 41 functional neuroimaging studies of executive function in schizophrenia. Arch. Gen. Psychiatry 66, 811-822. doi: 10. 1001/archgenpsychiatry.2009.91

Mitelman, S. A., Newmark, R. E., Torosjan, Y., Chu, K.-W., Brickman, A. M., Haznedar, M. M., et al. (2006). White matter fractional anisotropy and outcome in schizophrenia. Schizophr. Res. 87, 138-159. doi: 10.1016/j.schres.2006. 06.016

Mittleman, G., Goldowitz, D., Heck, D. H., and Blaha, C. D. (2008). Cerebellar modulation of frontal cortex dopamine efflux in mice: relevance to autism and schizophrenia. Synapse 62, 544-550. doi: 10.1002/syn.20525

Moghaddam, B., and Javitt, D. (2012). From revolution to evolution: the glutamate hypothesis of schizophrenia and its implication for treatment. Neuropsychopharmacology 37, 4-15. doi: 10.1038/npp.2011.181

Mouchet-Mages, S., Rodrigo, S., Cachia, A., Mouaffak, F., Olie, J. P., Meder, J. F., et al. (2011). Correlations of cerebello-thalamo-prefrontal structure and neurological soft signs in patients with first-episode psychosis. Acta Psychiatr. Scand. 123, 451-458. doi: 10.1111/j.1600-0447.2010.01667.x

Narayanan, N. S., Cavanagh, J. F., Frank, M. J., and Laubach, M. (2013). Common medial frontal mechanisms of adaptive control in humans and rodents. Nat. Neurosci. 16, 1888-1895. doi: 10.1038/nn.3549

Narayanan, N. S., Land, B. B., Solder, J. E., Deisseroth, K., and Dileone, R. J. (2012). Prefrontal D1 dopamine signaling is required for temporal control. Proc. Natl. Acad. Sci. U S A 109, 20726-20731. doi: 10.1073/pnas.12112 58109

Narayanan, N. S., Prabhakaran, V., Bunge, S. A., Christoff, K., Fine, E. M., and Gabrieli, J. D. E. (2005). The role of the prefrontal cortex in the maintenance of verbal working memory: an event-related FMRI analysis. Neuropsychology 19, 223-232. doi: 10.1037/0894-4105.19.2.223

Nopoulos, P. C., Ceilley, J. W., Gailis, E. A., and Andreasen, N. C. (1999). An MRI study of cerebellar vermis morphology in patients with schizophrenia: evidence in support of the cognitive dysmetria concept. Biol. Psychiatry 46, 703-711. doi: 10.1016/s0006-3223(99)00093-1

Oh, J. S., Kubicki, M., Rosenberger, G., Bouix, S., Levitt, J. J., McCarley, R. W., et al. (2009). Thalamo-frontal white matter alterations in chronic schizophrenia: a quantitative diffusion tractography study. Hum. Brain Mapp. 30, 3812-3825. doi: 10.1002/hbm.20809

Okubo, Y., Suhara, T., Suzuki, K., Kobayashi, K., Inoue, O., Terasaki, O., et al. (1997). Decreased prefrontal dopamine D1 receptors in schizophrenia revealed by PET. Nature 385, 634-636. doi: 10.1038/385634a0

Okugawa, G., Nobuhara, K., Sugimoto, T., and Kinoshita, T. (2005). Diffusion tensor imaging study of the middle cerebellar peduncles in patients with schizophrenia. Cerebellum 4, 123-127. doi: 10.1080/14734220510007879 
Okugawa, G., Sedvall, G. C., and Agartz, I. (2003). Smaller cerebellar vermis but not hemisphere volumes in patients with chronic schizophrenia. Am. J. Psychiatry 160, 1614-1617. doi: 10.1176/appi.ajp.160.9.1614

O'Leary, D. S., Andreason, N. C., Hurtig, R. R., Hichwa, R. D., Watkins, G. L., Ponto, L. L., et al. (1996). A positron emission tomography study of binaurally and dichotically presented stimuli: effects of level of language and directed attention. Brain Lang. 53, 20-39. doi: 10.1006/brln.1996.0034

Oliveri, M., Torriero, S., Koch, G., Salerno, S., Petrosini, L., and Caltagirone, C. (2007). The role of transcranial magnetic stimulation in the study of cerebellar cognitive function. Cerebellum 6, 95-101. doi: 10.1080/14734220701213421

Olney, J. W., and Farber, N. B. (1995). Glutamate receptor dysfunction and schizophrenia. Arch. Gen. Psychiatry 52, 998-1007. doi: 10.1001/archpsyc.1995. 03950240016004

Paradiso, S., Crespo Facorro, B., Andreasen, N. C., O’Leary, D. S., Watkins, L. G., Boles Ponto, L., et al. (1997). Brain activity assessed with PET during recall of word lists and narratives. Neuroreport 8, 3091-3096. doi: 10.1097/00001756199709290-00017

Parker, K. L., Alberico, S. L., Miller, A. D., and Narayanan, N. S. (2013a). Prefrontal D1 dopamine signaling is necessary for temporal expectation during reaction time performance. Neuroscience 255, 246-254. doi: 10.1016/j.neuroscience.2013. 09.057

Parker, K. L., Andreasen, N. C., Liu, D., Freeman, J. H., and O’Leary, D. S. (2013b). Eyeblink conditioning in unmedicated schizophrenia patients: a positron emission tomography study. Psychiatry Res. 214, 402-409. doi: 10. 1016/j.pscychresns.2013.07.006

Parker, K. L., Lamichhane, D., Caetano, M. S., and Narayanan, N. S. (2013c). Executive dysfunction in Parkinson's disease and timing deficits. Front. Integr. Neurosci. 7:75. doi: 10.3389/fnint.2013.00075

Parker, K. L., Zbarska, S., Carrel, A. J., and Bracha, V. (2009). Blocking GABAA neurotransmission in the interposed nuclei: effects on conditioned and unconditioned eyeblinks. Brain Res. 1292, 25-37. doi: 10.1016/j.brainres.2009.07.053

Parnaudeau, S., O’Neill, P.-K., Bolkan, S. S., Ward, R. D., Abbas, A. I., Roth, B. L., et al. (2013). Inhibition of mediodorsal thalamus disrupts thalamofrontal connectivity and cognition. Neuron 77, 1151-1162. doi: 10.1016/j.neuron.2013. 01.038

Picton, T. W., Stuss, D. T., Alexander, M. P., Shallice, T., Binns, M. A., and Gillingham, S. (2006). Effects of focal frontal lesions on response inhibition. Cereb. Cortex 17, 826-838. doi: 10.1093/cercor/bhk031

Pierce, K., and Courchesne, E. (2001). Evidence for a cerebellar role in reduced exploration and stereotyped behavior in autism. Biol. Psychiatry 49, 655-664. doi: 10.1016/s0006-3223(00)01008-8

Pomarol-Clotet, E., Canales-Rodríguez, E. J., Salvador, R., Sarró, S., Gomar, J. J., Vila, F., et al. (2010). Medial prefrontal cortex pathology in schizophrenia as revealed by convergent findings from multimodal imaging. Mol. Psychiatry 15, 823-830. doi: 10.1038/mp.2009.146

Prabhakaran, V., Rypma, B., Narayanan, N. S., Meier, T. B., Austin, B. P., Nair, V. A., et al. (2011). Capacity-speed relationships in prefrontal cortex. PLoS One 6:e27504. doi: 10.1371/journal.pone.0027504

Ragland, J. D., Laird, A. R., Ranganath, C., Blumenfeld, R. S., Gonzales, S. M., and Glahn, D. C. (2009). Prefrontal activation deficits during episodic memory in schizophrenia. Am. J. Psychiatry 166, 863-874. doi: 10.1176/appi.ajp.2009. 08091307

Rogers, T. D., Dickson, P. E., Heck, D. H., Goldowitz, D., Mittleman, G., and Blaha, C. D. (2011). Connecting the dots of the cerebro-cerebellar role in cognitive function: neuronal pathways for cerebellar modulation of dopamine release in the prefrontal cortex. Synapse 65, 1204-1212. doi: 10.1002/syn.20960

Rogers, T. D., Dickson, P. E., McKimm, E., Heck, D. H., Goldowitz, D., Blaha, C. D., et al. (2013). Reorganization of circuits underlying cerebellar modulation of prefrontal cortical dopamine in mouse models of autism spectrum disorder. Cerebellum 12, 547-556. doi: 10.1007/s12311-013-0462-2

Saalmann, Y. B., and Kastner, S. (2011). Cognitive and perceptual functions of the visual thalamus. Neuron 71, 209-223. doi: 10.1016/j.neuron.2011.06.027

Salgado-Pineda, P., Landin-Romero, R., Fakra, E., Delaveau, P., Amann, B. L., and Blin, O. (2014). Structural abnormalities in schizophrenia: further evidence on the key role of the anterior cingulate cortex. Neuropsychobiology 69, 52-58. doi: $10.1159 / 000356972$

Schmahmann, J. D. (1998). Dysmetria of thought: clinical consequences of cerebellar dysfunction on cognition and affect. Trends Cogn. Sci. 2, 362-371. doi: 10. 1016/s1364-6613(98)01218-2
Schmahmann, J. D. (2004). Disorders of the cerebellum: ataxia, dysmetria of thought and the cerebellar cognitive affective syndrome. J. Neuropsychiatry Clin. Neurosci. 16, 367-378. doi: 10.1176/appi.neuropsych.16.3.367

Schmahmann, J. D. (2010). The role of the cerebellum in cognition and emotion: personal reflections since 1982 on the dysmetria of thought hypothesis and its historical evolution from theory to therapy. Neuropsychol. Rev. 20, 236-260. doi: 10.1007/s11065-010-9142-x

Schulz, R., Wessel, M. J., Zimerman, M., Timmerman, J., Gerloff, C., and Hummel, F. C. (2014). White matter integrity of specific dentato-thalamo-cortical pathways is associated with learning gains in precise movement timing. Cereb. Cortex doi: 10.1093/cercor/bht356. [Epub ahead of print].

Schutter, D. J. L. G., van Honk, J., d' Alfonso, A. A. L., Peper, J. S., and Panksepp, J. (2003). High frequency repetitive transcranial magnetic over the medial cerebellum induces a shift in the prefrontal electroencephalography gamma spectrum: a pilot study in humans. Neurosci. Lett. 336, 73-76. doi: 10. 1016/s0304-3940(02)01077-7

Seeman, P. (1987). Dopamine receptors and the dopamine hypothesis of schizophrenia. Synapse 1, 133-152. doi: 10.1002/syn.890010203

Shevelkin, A. V., Ihenatu, C., and Pletnikov, M. V. (2014). Pre-clinical models of neurodevelopmental disorders: focus on the cerebellum. Rev. Neurosci. 25, 177194. doi: 10.1515/revneuro-2013-0049

Siegel, J. J., Kalmbach, B., Chitwood, R. A., and Mauk, M. D. (2012). Persistent activity in a cortical-to-subcortical circuit: bridging the temporal gap in trace eyelid conditioning. J. Neurophysiol. 107, 50-64. doi: 10.1152/jn.00689. 2011

Sivaswamy, L., Kumar, A., Rajan, D., Behen, M., Muzik, O., Chugani, D., et al. (2010). A diffusion tensor imaging study of the cerebellar pathways in children with autism spectrum disorder. J. Child Neurol. 25, 1223-1231. doi: 10. $1177 / 0883073809358765$

Snider, R. S., Maiti, A., and Snider, S. R. (1976). Cerebellar pathways to ventral midbrain and nigra. Exp. Neurol. 53, 714-728. doi: 10.1016/0014-4886(76) 90150-3

Stahl, S. M., and Buckley, P. F. (2007). Negative symptoms of schizophrenia: a problem that will not go away. Acta Psychiatr. Scand. 115, 4-11. doi: 10.1111/j. 1600-0447.2006.00947.x

Stoodley, C. J., and Schmahmann, J. D. (2009). The cerebellum and language: evidence from patients with cerebellar degeneration. Brain Lang. 110, 149-153. doi: 10.1016/j.bandl.2009.07.006

Strick, P. L., Dum, R. P., and Fiez, J. A. (2009). Cerebellum and nonmotor function. Annu. Rev. Neurosci. 32, 413-434. doi: 10.1146/annurev.neuro.31. 060407.125606

Sudarov, A. (2013). Defining the role of cerebellar Purkinje cells in autism spectrum disorders. Cerebellum 12, 950-955. doi: 10.1007/s12311-013-0490-y

Takayanagi, M., Wentz, J., Takayanagi, Y., Schretlen, D. J., Ceyhan, E., Wang, L., et al. (2013). Reduced anterior cingulate gray matter volume and thickness in subjects with deficit schizophrenia. Schizophr. Res. 150, 484-490. doi: 10.1016/j. schres.2013.07.036

Tomlinson, S. P., Davis, N. J., and Bracewell, R. M. (2013). Brain stimulation studies of non-motor cerebellar function: a systematic review. Neurosci. Biobehav. Rev. 37, 766-789. doi: 10.1016/j.neubiorev.2013.03.001

Tsubota, T., Ohashi, Y., Tamura, K., Sato, A., and Miyashita, Y. (2011). Optogenetic manipulation of cerebellar purkinje cell activity in vivo. PLoS One 6:e22400. doi: 10.1371/journal.pone.0022400

Uylings, H. B. M., Groenewegen, H. J., and Kolb, B. (2003). Do rats have a prefrontal cortex? Behav. Brain Res. 146, 3-17. doi: 10.1016/j.bbr.2003.09.028

Vilensky, J. A., and Van Hoesen, G. W. (1981). Corticopontine projections from the cingulate cortex in the rhesus monkey. Brain Res. 205, 391-395. doi: 10. 1016/0006-8993(81)90348-6

Vogt, B. A., Hof, P. R., Zilles, K., Vogt, L. J., Herold, C., and Palomero-Gallagher, N. (2013). Cingulate area 32 homologies in mouse, rat, macaque and human: cytoarchitecture and receptor architecture. J. Comp. Neurol. 521, 4189-4204. doi: $10.1002 /$ cne.23409

Vogt, B. A., and Paxinos, G. (2014). Cytoarchitecture of mouse and rat cingulate cortex with human homologies. Brain Struct. Funct. 219, 185-192. doi: 10. 1007/s00429-012-0493-3

Volz, H.-P., Nenadic, I., Gaser, C., Rammsayer, T., Häger, F., and Sauer, H. (2001). Time estimation in schizophrenia: an fMRI study at adjusted levels of difficulty. Neuroreport 12, 313-316. doi: 10.1097/00001756-20010212000026 
Walker, E., and Shaye, J. (1982). Familial schizophrenia. A predictor of neuromotor and attentional abnormalities in schizophrenia. Arch. Gen. Psychiatry 39, $1153-$ 1156. doi: 10.1001/archpsyc.1982.04290100027005

Wassink, T. H., Andreasen, N. C., Nopoulos, P., and Flaum, M. (1999). Cerebellar morphology as a predictor of symptom and psychosocial outcome in schizophrenia. Biol. Psychiatry 45, 41-48. doi: 10.1016/s0006-3223(98)00175-9

Watson, T. C., Becker, N., Apps, R., and Jones, M. W. (2014). Back to front: cerebellar connections and interactions with the prefrontal cortex. Front. Syst. Neurosci. 8:4. doi: 10.3389/fnsys.2014.00004

Watson, T. C., Jones, M. W., and Apps, R. (2009). Electrophysiological mapping of novel prefrontal - cerebellar pathways. Front. Integr. Neurosci. 3:18. doi: 10. 3389/neuro.07.018.2009

Weinberger, D. R., Berman, K. F., and Zec, R. F. (1986). Physiologic dysfunction of dorsolateral prefrontal cortex in schizophrenia. I. Regional cerebral blood flow evidence. Arch. Gen. Psychiatry 43, 114-124. doi: 10.1001/archpsyc.1986. 01800020020004

Weinberger, D. R., Kleinman, J. E., Luchins, D. J., Bigelow, L. B., and Wyatt, R. J. (1980). Cerebellar pathology in schizophrenia: a controlled postmortem study. Am. J. Psychiatry 137, 359-361.

Weiss, C., and Disterhoft, J. F. (1996). Eyeblink conditioning, motor control and the analysis of limbic-cerebellar interactions. Behav. Brain Sci. 19, 479-481. doi: 10. $1017 / \mathrm{s} 0140525 \times 00081929$

White, T., Nelson, M., and Lim, K. O. (2008). Diffusion tensor imaging in psychiatric disorders. Top. Magn. Reson. Imaging 19, 97-109. doi: 10.1097/rmr. 0b013e3181809fle

Williams, S. M., and Goldman-Rakic, P. S. (1998). Widespread origin of the primate mesofrontal dopamine system. Cereb. Cortex 8, 321-345. doi: 10. 1093/cercor/8.4.321
Wiser, A. K., Andreasen, N. C., O’Leary, D. S., Watkins, G. L., Boles Ponto, L. L., and Hichwa, R. D. (1998). Dysfunctional cortico-cerebellar circuits cause "cognitive dysmetria” in schizophrenia. Neuroreport 9, 1895-1899. doi: 10.1097/00001756199806010-00042

Wu, T., and Hallett, M. (2013). The cerebellum in Parkinson's disease. Brain 136, 696-709. doi: 10.1093/brain/aws360

Yücel, M., Pantelis, C., Stuart, G. W., Wood, S. J., Maruff, P., Velakoulis, D., et al. (2002). Anterior cingulate activation during Stroop task performance: a PET to MRI coregistration study of individual patients with schizophrenia. Am. J. Psychiatry 159, 251-254. doi: 10.1176/appi.ajp.159. 2.251

Conflict of Interest Statement: The authors declare that the research was conducted in the absence of any commercial or financial relationships that could be construed as a potential conflict of interest.

Received: 01 March 2014; accepted: 22 August 2014; published online: 15 September 2014.

Citation: Parker KL, Narayanan NS and Andreasen NC (2014) The therapeutic potential of the cerebellum in schizophrenia. Front. Syst. Neurosci. 8:163. doi: $10.3389 /$ fnsys. 2014.00163

This article was submitted to the journal Frontiers in Systems Neuroscience.

Copyright (c) 2014 Parker, Narayanan and Andreasen. This is an open-access article distributed under the terms of the Creative Commons Attribution License (CC BY). The use, distribution or reproduction in other forums is permitted, provided the original author(s) or licensor are credited and that the original publication in this journal is cited, in accordance with accepted academic practice. No use, distribution or reproduction is permitted which does not comply with these terms. 